\title{
Sofrimento psíquico em familiares de usuários de um Centro de Atenção Psicossocial (CAPS)*
}

Renata Fabiana Pegoraro ${ }^{1}$

Regina Helena Lima Caldana

PEGORARO, R.F.; CALDANA, R.H.L. Psychological stress among relatives of users of a Psychosocial Care Center. Interface - Comunic., Saúde, Educ., v.12, n.25, p.295-307, abr./jun. 2008.

Psychological stress among the families of users of a Psychosocial Care Center in the interior of the State of São Paulo was investigated. Nine family members identified as caregivers of these users participated: they were mostly female, aged 60-76 years and from lower social classes. A semi-structured guide was used for the interviews, covering the caregiver's freely reported life history, the meaning attributed to caring and the impact of mental illness on the interviewees' and relatives' lives. Thematic analysis on the interviews enabled identification of psychological stress (nervousness and depression) among these relatives, including caregivers, and administration of psychiatric treatment using anxyolitic drugs. The presence of mental stress not only in the user but also among family members may imply greater burden on the caregiver, because of the accumulation of tasks, and may indicate the need for attention and intervention among families by healthcare teams.

Key words: Caregivers. Psychological stress. Mental health. Family relations.
Investiga-se o sofrimento psíquico em familiares de usuários de um Centro de Atenção Psicossocial (CAPS) do interior paulista. Participaram do estudo nove familiares identificados como cuidadores desses usuários, em sua maioria do sexo feminino, com idades entre 60-76 anos e pertencentes às camadas populares. Utilizou-se um roteiro de entrevista semi-estruturada, abordando o relato livre da história de vida do cuidador, o sentido atribuído ao cuidar e o impacto da doença mental no cotidiano dos entrevistados e familiares. A análise temática das entrevistas permitiu a identificação de sofrimento psíquico (nervoso e depressão) em familiares, inclusive cuidadores, e realização de tratamento psiquiátrico com uso de ansiolíticos. A presença de sofrimento mental em familiares, além do usuário, pode implicar mais sobrecarga para o cuidador, em virtude do acúmulo de tarefas, e indica necessidade de atenção e intervenção junto às famílias por parte das equipes de saúde.

Palavras-chave: Cuidadores. Estresse psicológico. Saúde mental. Relações familiares.

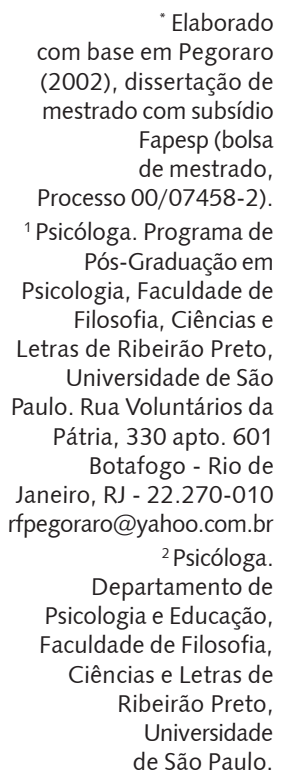

"Elaborado com base em Pegoraro (2002), dissertação de mestrado com subsídio Fapesp (bolsa de mestrado, Processo 00/07458-2). ${ }^{1}$ Psicóloga. Programa de Pós-Graduação em Psicologia, Faculdade de Filosofia, Ciências e Letras de Ribeirão Preto,

Universidade de São Paulo. Rua Voluntários da Pátria, 330 apto. 601 Botafogo - Rio de Janeiro, RJ - 22.270-010 rfpegoraro@yahoo.com.br 2 Psicóloga. Departamento de Psicologia e Educação, Faculdade de Filosofia, Ciências e Letras de Ribeirão Preto, Universidade de São Paulo. 


\section{Introdução}

No Brasil, a atual política de saúde mental, ao incentivar a criação de serviços alternativos ao modelo asilar, evidencia a necessidade de inclusão da família do paciente psiquiátrico no tratamento, tanto para proporcionar suporte ao membro doente, como para receber ela mesma cuidados específicos (Brasil, 2004, 2002; Oliveira, Loyola, 2004; Pegoraro, 2002).

A família pode ser classificada como um locus do cuidado, espaço indispensável da sobrevivência, do desenvolvimento e da proteção integral de filhos e demais membros, independentemente do arranjo ou da forma como se estruture (Pinho, Kantorski, 2004; Ferrari, Kaloustian, 1998; Maurás, Kayayan, 1998).

Ao escutar a família, o profissional da área de saúde pode descobrir quais cuidados se fazem necessários, bem como verificar que o sofrimento não é exclusivo daquele que se encontra doente (Cesarino, 1989). Investigar, junto a familiares e usuários, sua percepção sobre o desencadeamento, o curso, o impacto no cotidiano e formas de tratamento dos que se encontram em sofrimento mental, permite a instrumentalização das equipes na avaliação do grau de crítica da realidade e dos conhecimentos sobre a doença que familiares/usuários possuem (Luis, Margiotte, Santos, 1989). Tais percepções a respeito da saúde ou da doença, compartilhadas por familiares e usuários, sofrem influência de seu contexto cultural, religioso, econômico, indicando a necessidade de que o contexto de vida das famílias seja, também, considerado (Melman, 2002; Osinaga, 1999).

Um dos aspectos que merecem investigação junto a familiares é a presença da sobrecarga na prestação de cuidados ao usuário (Pegoraro, Caldana, 2006; Rose, Mallinson, Gerson, 2006; Bandeira, Barroso, 2005; Magliano et al., 2005; Lowyck et al., 2004; King et al., 2003; Lauber et al., 2003; Rosa, 2003; Furegato et al., 2002; Melman, 2002). Conhecer a sobrecarga vivenciada pelos familiares permite traçar intervenções que: auxiliem na interação e gestão da vida cotidiana dos pacientes, contribuam para aliviar o peso dos encargos, facilitem a cooperação, diminuam os fatores estressantes que podem desencadear crises. Tais intervenções permitem melhorar a qualidade de vida dos envolvidos, aumentar o suporte e a qualidade de vida das famílias e, conseqüentemente, terão reflexos em ações voltadas para a reinserção social. Além disso, a intervenção profissional pode auxiliar na prevenção de transtornos psicológicos em familiares decorrentes da sobrecarga advinda do cuidar (Bandeira, Barroso, 2005; Melman, 2002).

É sobre o familiar que se encarrega mais intensamente dos cuidados que a sobrecarga recai mais significativamente. O cuidador torna-se, deste modo, figura central no planejamento das ações de saúde executadas pelas equipes de saúde mental; e sua "principal ferramenta", segundo Rosa (2001), seria conhecer as formas como o cuidador lida com seus sentimentos, suas atitudes, suas angústias, necessidades e desconfortos provocados no processo de cuidar. Em outras palavras, para que "cuidem do cuidador", as equipes precisam, primeiramente, conhecê-lo.

Não raro o cuidado exercido no lar, pela família, ao usuário é executado pela mulher (Pereira, 2003; Rosa, 2003; Pegoraro, 2002; Gonçalves, Sena, 2001). Quando pertencente às camadas populares, a mulher que cuida do portador de sofrimento mental acumula outros encargos a esta tarefa, como: a manutenção da limpeza da casa, a alimentação do grupo familiar, e, mesmo, o cuidado a outras pessoas, como crianças e doentes, membros da família.

Em virtude da necessidade de ampliar os conhecimentos sobre as famílias dos usuários de serviços públicos de saúde mental em nosso meio, com especial destaque para os cuidadores, estabeleceu-se, como objetivo do presente artigo, identificar a presença de histórico de sofrimento psíquico em familiares de usuários de um Centro de Atenção Psicossocial (CAPS), e formas de ajuda procuradas pelos mesmos, com base em suas histórias de vida.

\section{Metodologia}

O presente estudo é parte de uma pesquisa de maior amplitude (Pegoraro, 2002), cujo objetivo foi investigar o sentido do cuidar de um familiar portador de sofrimento mental à luz da história de vida de responsáveis por usuários de um CAPS do interior paulista e de seu contexto de vida atual. 


\section{Sujeitos}

Foram entrevistados nove familiares de usuários de um CAPS do interior paulista, localizado em um município com menos de trinta mil habitantes, que prestava atendimento a portadores de transtornos mentais, residentes no município sede e em outras duas cidades da microrregião.

Os critérios utilizados para a seleção dos entrevistados foram: apresentar disponibilidade para fornecer entrevista longa, gravada, mediante sigilo de identificação e assinatura do Termo de Consentimento Livre e Esclarecido; ser considerado, pela equipe do CAPS, como o "cuidador" do usuário, e, com o intuito de viabilizar a realização das entrevistas, que fosse procedente do município no qual o serviço se localizava.

Pelo termo "cuidador" compreendemos uma pessoa que, à época, prestava cuidados informais (não técnicos e não remunerados) a um usuário do CAPS, considerado como o responsável pelo usuário (aquele a quem a equipe aciona/procura em caso de necessidade).

O critério utilizado para o encerramento da coleta foi o "ponto de saturação" de novas informações, tal qual propõe Bertaux (1980).

\section{Modalidade de entrevista e instrumento utilizado}

O uso da modalidade de entrevista denominada "história de vida" tem como objetivo identificar os aspectos que, ao depoente, e não ao pesquisador, parecem importantes na reconstituição de sua história pessoal (Caldana, 1998). A entrevista de "história de vida" permite tanto a apreensão de acontecimentos vividos e experiências adquiridas ao longo da trajetória do entrevistado, quanto delinear as relações entre o depoente e os grupos sociais a que pertence (Queiroz, 1987).

Com o intuito de "captar" as escolhas dos cuidadores na elaboração de sua história pessoal ou a forma como o entrevistado se posiciona em relação ao passado, bem como investigar uma série de aspectos ligados à tarefa de cuidar, optou-se por uma modalidade de entrevista de história de vida utilizada por Caldana (1998) e aqui denominada "história de vida temática". Tal modalidade permite que, inicialmente, o depoente dê o rumo que desejar na reconstituição de sua história pessoal e, finalizada esta parte espontânea do depoimento, o pesquisador pode colocar questões mais diretivas, de interesse específico de seu trabalho e que porventura não tenham sido abordadas espontaneamente pelo depoente, utilizando, para isso, um roteiro de tópicos previamente definidos, cujo objetivo é compreender o posicionamento do entrevistado em relação ao tema em estudo (Caldana, 1998).

O modelo adotado por Caldana aproxima-se da "história de vida inacabada" ou "sumária" discutida por Demartini (1992), cuja vantagem, frente à história de vida, estaria na possibilidade de aliar a concessão de liberdade ao entrevistado a certo nível de focalização em entrevistas mais breves, o que permite a realização de um maior número de entrevistas. Demartini (1992), no entanto, não faz uso de um roteiro de tópicos (temáticas) definido previamente à entrevista, e por este motivo, preferimos adotar aqui a nomenclatura "história de vida temática" para descrever o roteiro empregado, composto por três momentos: a) inicialmente, questões sobre dados pessoais que permitissem a caracterização dos depoentes, b) seguidas pelo relato da história pessoal e, finalmente, c) questões temáticas ou tópicos que versaram sobre o cotidiano de vida familiar, as tarefas desempenhadas por cada membro nesta rotina, as dificuldades enfrentadas mediante o adoecimento psíquico de um dos membros e as informações recebidas a este respeito.

Enquanto a "história de vida" permanece centrada no relato de impressões e subjetividades, sempre em busca de captar, de modo mais livre, o sentido que as experiências vivenciadas pelo sujeito apresentam segundo o seu próprio ponto de vista, a "história de vida temática" compromete-se com o esclarecimento ou com a opinião do entrevistado sobre um determinado evento. No caso deste estudo, a temática de interesse relacionava-se aos cuidados prestados, pelo entrevistado, ao familiar assistido pelo CAPS. 


\section{Forma de análise de dados}

De modo sintético, podemos dizer que a análise das entrevistas foi orientada por meio de algumas etapas, embasadas no que descrevem Biasoli-Alves e Dias da Silva (1992) a respeito da apreensão de temas no conjunto das entrevistas efetuadas pelo pesquisador:

- Leitura exaustiva e repetida das entrevistas, para apreensão de idéias centrais e momentos-chave quanto ao tema, tendo como pano de fundo os dados complementares;

- Identificação de temas, inicialmente, em cada entrevista e, depois, no conjunto de entrevistas, para a formação de categorias centrais;

- Sistematização de categorias centrais como fruto de constante movimento entre os dados, a abordagem conceitual e a literatura, até a composição de um quadro significativo de análise;

- Redação final da análise dos dados visando vinculação com a realidade de modo que os indicativos do trabalho de pesquisa possam vir a embasar reflexões sobre a prática profissional na área.

Esses passos permitiram a formação das categorias de análise. O presente artigo propõe-se a discutir parte do material referente à categoria "concepções dos cuidadores a respeito da doença mental e os cuidados requeridos", mais especificamente o subtema "sofrimento mental em familiares segundo a percepção dos cuidadores".

\section{Procedimentos éticos}

O estudo teve início após aprovação do projeto pelo Comitê de Ética em Pesquisa da Escola de Enfermagem de Ribeirão Preto, Universidade de São Paulo. Foi utilizado o Termo de Consentimento Livre e Esclarecido no momento da realização das entrevistas e, como forma de garantir o sigilo quanto à identificação dos participantes, os nomes dos participantes ou aqueles que foram citados nas entrevistas foram alterados.

Antes do contato com o cuidador, o usuário foi sempre informado, pela equipe do CAPS, sobre o desenvolvimento da pesquisa, tendo sido verificada a existência de alguma restrição de sua parte. Embora o usuário não seja um sujeito da pesquisa, e o roteiro não investigue diretamente aspectos a seu respeito, sua pessoa não deixa de estar presente de forma importante nos relatos, portanto a atitude de informar o usuário sobre o projeto fundamenta-se no respeito ao mesmo.

\section{Resultados}

\section{Breve caracterização dos entrevistados}

Do total de nove cuidadores entrevistados (Tabela 1), oito eram mulheres (seis mães, uma avó e uma irmã de usuários do CAPS), a maior parte entre sessenta e oitenta anos, ensino fundamental incompleto, viúvas ou casadas, exerciam atividades relacionadas às tarefas manuais e ao lar, e pertenciam a diferentes religiões. O único homem entrevistado era pai de um usuário, tinha 76 anos, era casado, católico, ensino fundamental incompleto, exercera profissão de pedreiro e encontrava-se aposentado.

A renda familiar declarada pelos entrevistados, suas condições de moradia e de vida permitem classificá-los como pertencentes às "camadas populares", expressão que, segundo Romanelli (1997), designa a população cujas condições de vida são precárias e niveladas pela pobreza, ou seja, a renda é reduzida, a moradia e o transporte são precários, o atendimento médico e o saneamento básico são deficientes.

As histórias de vida dos cuidadores entrevistados apresentaram alguns pontos em comum que merecem destaque: de origem rural, a maior parte dos entrevistados passou a residir na zona urbana apenas após o casamento. Suas lembranças a respeito da infância e mocidade são marcadas pela tenra inserção no mundo do trabalho, seja no apoio às tarefas de manutenção do lar, no caso das mulheres, seja no auxílio à manutenção da propriedade rural, no caso do cuidador entrevistado. Foi o trabalho 
também a marca assinalada pelos entrevistados ao longo da vida: o nascimento dos filhos, somado às dificuldades financeiras, moldaram um dia-a-dia baseado no exercício de múltiplas tarefas, seja no caso de mulheres que buscaram a inserção no mercado de trabalho para auxiliar na composição da renda mensal e continuaram a exercer as tarefas domésticas, seja no caso daquelas que se mantiveram apenas no ancoramento da família, permitindo que o marido estivesse voltado apenas para as atividades geradoras de renda.

Tabela 1. Dados de caracterização dos cuidadores entrevistados.

\begin{tabular}{|c|c|c|c|c|c|c|c|c|}
\hline Cuidador & Sexo & Idade & $\begin{array}{l}\text { Estado } \\
\text { civil }\end{array}$ & Escolaridade & Profissão & $\begin{array}{c}\text { Ocupação } \\
\text { atual }\end{array}$ & Religião & $\begin{array}{l}\text { Parentesco } \\
\text { com usuário }\end{array}$ \\
\hline Úrsula & $\mathrm{F}$ & 60 & Viúva & Analfabeta & Trabalhadora rural & Do lar & Evangélica & Mãe \\
\hline Dulce & $\mathrm{F}$ & 77 & Viúva & Fundamental incompleto & Doméstica/serviços gerais & Aposentada & Evangélica & Mãe \\
\hline Teresa & $\mathrm{F}$ & 70 & Viúva & Fundamental incompleto & Do lar & Do lar & Católica & Mãe \\
\hline Catarina & $\mathrm{F}$ & 80 & Viúva & Analfabeta & Do lar & Do lar & Católica & Mãe \\
\hline Cíntia & $\mathrm{F}$ & 70 & Casada & Analfabeta & Do lar & Do lar & Católica & Mãe \\
\hline Sérgio & $M$ & 76 & Casado & Fundamental incompleto & Pedreiro & Aposentado & Católico & Pai \\
\hline Selena & $\mathrm{F}$ & 60 & Casada & Fundamental incompleto & Do lar & Do lar & Evangélica & Mãe \\
\hline Olga & $\mathrm{F}$ & 60 & Casada & Fundamental incompleto & Doméstica & Vigia & Evangélica & Avó \\
\hline Noêmia & $\mathrm{F}$ & 28 & Casada & Médio completo & Balconista & Do lar & Espírita & Irmã \\
\hline
\end{tabular}

\section{Análise de entrevistas}

\section{Familiares com histórico de sofrimento psíquico}

As entrevistas revelaram que, dos nove cuidadores entrevistados, seis possuíam familiares (filhos, marido, netos, irmãs), que enfrentaram ou ainda enfrentavam, à data da coleta, situações descritas como depressão, nervoso, desgaste emocional e ideação suicida (Tabela 2).

Tabela 2. Familiares dos cuidadores entrevistados com problemas de saúde mental e tipo de ajuda procurada.

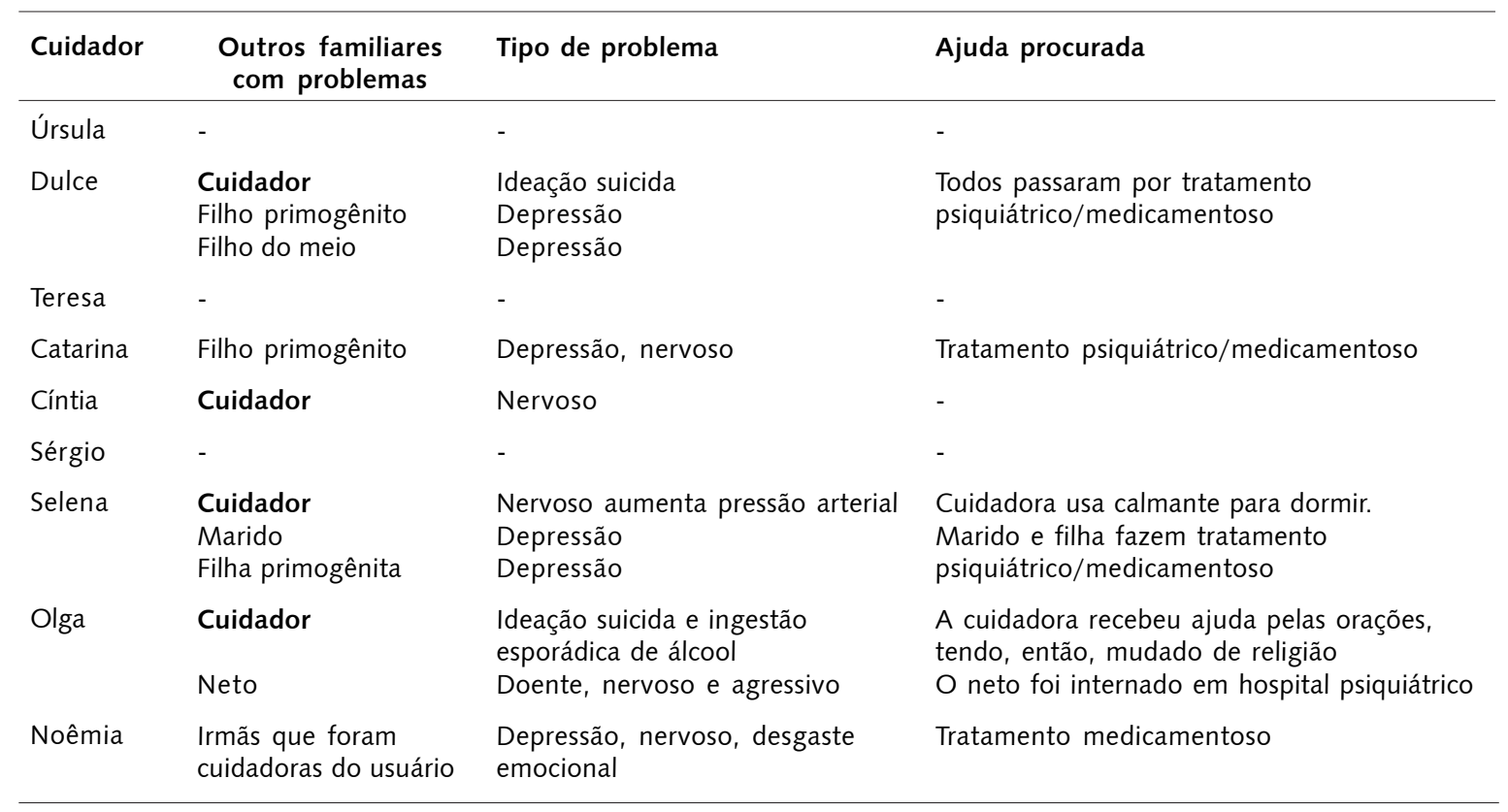


O sofrimento psíquico dos familires encontrava-se, em alguns casos, ligado à sobrecarga pelo cuidado exercido e, em outros, era independente ou anterior à atividade de cuidar.

A) Sofrimento psíquico ligado à sobrecarga

Nestes casos, os familiares com histórico de sofrimento psíquico exerciam tarefas de cuidado no diaa-dia do usuário, no geral, auxiliando o entrevistado, que solicitava a realização de algumas atividades, como acompanhar o usuário ao médico ou pagar contas da casa. O sofrimento gerado pelo exercício do cuidado pode ser ilustrado pelo relato de Noêmia. Nos momentos em que o irmão de Noêmia encontrava-se em crise, e requeria cuidados mais intensos, esta acionava as duas irmãs, solicitando que elas observassem o rapaz, de modo que não fugisse de casa ou tentasse suicídio. As duas irmãs de Noêmia revezavam-se neste cuidado auxiliar e apresentaram, segundo a entrevistada, sintomas de nervoso, depressão e desgaste emocional (Tabela 2) em decorrência destas atividades. Os cuidados prestados pelas irmãs foram interrompidos e houve procura por ajuda médica para lidar com a situação.

O cuidado direto (cuidar da alimentação, da vestimenta, da medicação) era sempre exercido pelo entrevistado que, em alguns casos, também apresentava sofrimento psíquico referente à sobrecarga. Dentre os familiares que passaram por sofrimento mental incluem-se algumas das entrevistadas (Tabela 2): Dulce, Cíntia, Selena e Olga.

B) Sofrimento psíquico não relacionado ou anterior à sobrecarga

Em outros casos, como os relatados por Dulce, Catarina e Selena (Tabela 2), o sofrimento de familiares não estava relacionado à sobrecarga no cuidar do usuário do CAPS. Suas histórias retrataram situações por elas caracterizadas como "depressão", que teria atingido filhos e/ou marido e haviam-se somado às dificuldades financeiras vividas no dia-a-dia. No caso de Selena, os episódios ocorreram em paralelo com o cuidado exercido junto à filha, usuária do CAPS, e requisitaram que a entrevistada assumisse mais uma responsabilidade em seu dia-a-dia, cuidar do marido que adoecera. Além das dificuldades financeiras enfrentadas pela família de Selena e da doença da filha, atendida no CAPS, dois outros filhos envolveram-se com a venda de drogas e a polícia, com freqüência, ia à sua casa, o que teria desencadeado a depressão da qual, até o momento da entrevista, sofria seu marido, quadro que requisitava os cuidados da esposa: "É por causa de taaaanta... assim, nervoso, dos filhos, aquelas policial, aquelas coisa... quando eles vinha, eles vinha com tudo e a gente sustava... e ele [marido] começou a ficar doente". (Selena)

\title{
C) Sofrimento psíquico em cuidadores
}

Dentre os familiares que passaram por sofrimento mental incluem-se algumas das entrevistadas (Tabela 2): Dulce, Cíntia, Selena e Olga. Em determinados relatos, como de Dulce e Olga, é possível observar, em certas fases de suas vidas, episódios de sofrimento intenso, inclusive com ideação suicida:

\author{
Aí um dia eu... estava muito doente, sabe? Muuuuito nervosa, estava muito nervosa. [...] eu \\ gostaria, sempre gostava de ficar em lugar escuro, eu tinha muito medo. [...] eu tinha \\ vontade de me matar. [...] Num sei por que que... eu não sei por que isso entrava no meu \\ pensamento, deu tirar minha própria vida! (Olga)
}

O sofrimento apresentado por estas duas cuidadoras é anterior à doença do usuário. Remonta à época em que seus filhos ainda eram crianças. Dulce trabalhava para sustentar o marido e os filhos pequenos, e Olga fazia uso de bebida alcoólica, tendo também filhos menores de 18 anos.

\section{Procura por ajuda: tratamento médico, uso de medicação e religião}

A busca por ajuda médica e o uso de medicação psiquiátrica esteve presente em todos os casos de familiares que enfrentaram situações de sofrimento psíquico (Tabela 2). Esta prática é tida como eficaz e necessária de acordo com o entrevistado.

A medicação esteve presente em todos os relatos, desde quadros de "nervoso" ou depressão até aqueles onde era freqüente a ideação suicida (Tabela 2). Alguns relatos revelaram que o familiar procurou ajuda em tratamento psiquiátrico de tipo ambulatorial/medicamentoso e a internação psiquiátrica chegou a ser indicada, em alguns casos, e a ocorrer, em outros, quando aparecia relacionada a agressividade. 
O uso de "calmante" se fez presente para eliminar o "nervoso", fruto dos dissabores do cotidiano e/ou do desgaste desencadeado pelo auxílio ao cuidado com o usuário. Assim, as causas para o problema são variadas e podem envolver uma somatória de acontecimentos que, por provocarem muita tensão, são identificados como desencadeadores do mesmo.

A procura por tratamento médico encontrava-se vinculada à existência de serviço de saúde mental nas proximidades da residência do familiar, bem como estava de acordo com sua "crença religiosa". Assim, para um fiel evangélico, a ajuda recebida foram as orações proferidas durante um culto, na igreja que freqüentava, por meio do qual dá-se a expulsão do demônio, a razão do problema. Selena assim explica a situação:

Espiritual é uma doença que muitas das vezes o médico está ali lutando... lutando e não consegue. E muitas das vezes com uma oração, a enfermidade vai embora e você fica boa. É espiritual. [...] Nós tem que ter uma devoção com Deus, ou na católica, ou... na minha, evangélica. Mas tem que ter uma devoção. Colocar sempre Deus na frente e nós atrás. [...] Que a perturbação muitas das vezes, não é, não vem tanto da doença, vem do, do lado do maligno! [...] Maligno é o lado diabólico de... de... você sabe. (Selena)

\section{Capacidade de exercer trabalho: marco divisor entre sofrimento dos familiares e do usuário do CAPS}

Os relatos sobre a presença de desconforto psíquico em familiares, mesmo que constante ou intenso, classificavam-no como de menor gravidade que o sofrimento apresentado pelo usuário do CAPS. Era a manutenção do indivíduo no trabalho, do qual tirava seu sustento, que diferenciava o tipo de sofrimento apresentado por familiares e usuários do CAPS: enquanto os demais familiares, mesmo em sofrimento psíquico, haviam dado continuidade às atividades das quais retiravam seu sustento, nenhum dos usuários do CAPS trabalhava no momento de realização das entrevistas. Aqueles usuários que haviam exercido uma atividade remunerada, haviam-na abandonado mediante o aparecimento da doença. Em alguns casos, segundo o relato do cuidador, o usuário poderia ter adoecido em virtude do trabalho (em excesso ou por sua falta), e a impossibilidade de a ele retornar demarcava a existência da doença. Enquanto "nervosos" ou "deprimidos", os demais familiares, pela manutenção do vínculo de trabalho, eram vistos como portadores de um sofrimento de menor gravidade, se comparado ao do usuário, ceifado em sua possibilidade de exercer trabalho.

Catarina utiliza o trabalho para comparar as situações vividas pelo filho primogênito, que teria sofrido de depressão, e Jesus, usuário do CAPS:

Diferente. Depressão, [o primogênito] tem depressão, muita, muito problema, né? Que nem o Jesus [usuário do CAPS], não tem, não. [...] [Jesus] Ficava nervoso, né, que dava nervoso, chorava. [...] Mas ele [primogênito] ia trabalhar a mesma coisa. [...] [O Jesus] não voltou mais nem mais pra trabalhar. (Catarina)

Também Olga tece suas considerações sobre o exercício do trabalho como marca da gravidade do sofrimento psíquico: "Ele pensava normal, tudo normal! [...] Ah, ele trabalhava de serviço... assim, servente de pedreiro [...] Mas depois que ele largou... Começou já ficar nervoso, já começou, sabe, falar, falar sozinho..." (Olga, falando do outro neto, irmão do usuário do CAPS).

$\mathrm{Na}$ visão dos entrevistados, os familiares que passaram por problemas de saúde mental tendiam a aceitar mais facilmente alguns comportamentos do usuário, os quais freqüentemente incomodavam o cuidador e/ou componentes do grupo. Certa solidariedade entre os familiares e o usuário era criada pela vivência de situações de sofrimento psíquico. 


\section{Discussão}

As explicações fornecidas pelos cuidadores a respeito do sofrimento mental em familiares transitaram entre o universo científico, com o emprego de termos médicos e a busca por atendimento psiquiátrico, e o universo cultural das famílias, pertencentes às camadas populares, cujos indicativos são o uso da expressão nervoso/nervosismo, a importância do trabalho como sinal de saúde do indivíduo, e a crença religiosa do cuidador.

Essas diferentes explicações, no entanto, ao coexistirem, não demarcariam uma contradição. Como aponta Minayo (1998), dentre as camadas populares, às quais pertencem os entrevistados, a concepção de saúde e de doença é ampla, e várias podem ser as formas aceitas de explicação. Assim sendo, não haveria qualquer contradição entre ir ao médico e procurar outros tipos de auxílio, como aqueles advindos da religião seguida (Minayo, 1998). Haveria um trânsito possível ao enfermo ou seus familiares em busca da compreensão de sua doença e de como poderia ocorrer a cura. Diferentes modelos etiológicos e terapêuticos podem ser acionados no caminho de busca por compreender de que se sofre e como ser curado (Romanelli, 1997).

A concepção dominante de saúde e doença em nossa sociedade pressupõe algo organicamente localizado, a ser tratado por remédios, por cirurgias, ou seja, é a reprodução do modelo biomédico de saúde (Oliveira, 1998); e, neste sentido, vale a pena destacar as descrições feitas pelos cuidadores sobre o problema e embasadas na existência de uma localização física da doença psiquiátrica. A este respeito, Minayo (1998) destaca que, ao falar sobre suas doenças, as camadas populares abordariam, em realidade, uma série de episódios vividos em seu dia-a-dia, que extrapolam a visão biomédica predominante entre os profissionais de saúde. Como resposta, muitos desses profissionais assinalariam a inadequação da forma empregada pelos pacientes para relatarem o que sentem e do que sofrem. Mais interessante seria olhar pelo prisma apontado pela autora, que avalia que, em muitos casos, a linguagem própria empregada pelas camadas populares questionaria o saber médico, por retratar situações que extrapolam o sujeito biofisiológico.

É importante ainda que alguns trechos das entrevistas trazem à tona a noção de que, aos olhos do cuidador, a explicação dos médicos sobre formas de funcionamento mental não satisfazem a necessidade do familiar em compreender aquilo que está acontecendo com aquele de quem cuida. Como o entendimento perpassa pela idéia de concretude, as explicações sobre o dinamismo mental, e, ainda, aquelas que comportam termos técnicos, de psicopatologia, estão muito distantes do universo compartilhado pelos entrevistados. Isto não significa que os familiares tenham uma gama limitada de compreensão sobre o fenômeno, que não sejam capazes de compreender o que lhes é comunicado; apenas que do modo como isto é feito, com os termos utilizados, não se consegue atingir o seu modo de se relacionar com a doença.

O termo usado para explicar o quadro apresentado pelo usuário e os demais familiares pode ser o mesmo ("nervoso", "depressão"), o remédio ingerido também, assim como um médico que prescreva a receita, mas a gravidade do problema parece demarcar a diferença: apenas o usuário deixou de ou não chegou a trabalhar.

Na literatura, o "nervoso" aparece relacionado ao trabalho e ao surgimento de doenças entre a população pertencente às camadas populares. Na fala dos cuidadores, o termo foi usado com referência à incidência de crise do usuário, a situações onde alguns sintomas dos usuários permanecem de modo mais crônico, ou a outras situações de tensão entre os familiares. Desta forma, em alguns casos, o nervoso não aparece como uma situação desencadeada por determinados fatos, mas como um estado permanente, que acompanha o indivíduo, e encontra-se aparentemente relacionado à tensão que toma parte de seu cotidiano (Cardoso, 1999; Traverso, Medeiros, 2004). Estar ou ter a cabeça fraca, dentro do quadro de "nervosismo", seria um estado de perturbação maior, que afeta o desempenho das funções. Na escala hierárquica do "nervoso", a loucura seria o maior grau. Se ela escapa ao controle terapêutico e social, ocorre a preferência pelo medicamento psicotrópico (calmante para uso regular) em detrimento de recursos terapêuticos do "conversar" (Cardoso, 1999).

Tido como causa da doença de alguns usuários do CAPS (pelo excesso em seu exercício ou por abandono/interrupção abrupta), o trabalho é também a linha tênue que separa a gravidade do 
sofrimento mental: de um lado, estariam os familiares que vivenciaram situações menos graves, como nervosismo e depressão, e de outro, os familiares que realizavam tratamento no CAPS, e que precisavam de cuidados médicos contínuos. A menor gravidade do quadro apresentado pelos familiares que não se tratavam no CAPS repousava no não-abandono do trabalho. Continuar trabalhando, mesmo nos momentos de nervoso e depressão, era sinal de que se tratava de um problema menos grave, pois se encontrava preservada a capacidade de dedicar-se ao trabalho. O exercício do trabalho também era um indicativo de maiores condições de saúde por parte dos usuários do CAPS, pois, de acordo com os entrevistados, o início de atividade de trabalho, mesmo que em oficina protegida, era sinal de melhora, de possibilidade de cura da doença mental.

Para as camadas populares, a doença implicaria a impossibilidade de trabalhar, de realizar afazeres rotineiros, denotando que a concepção de saúde e doença está relacionada à atividade física e capacidade para o trabalho. A doença aparece relacionada ao não-trabalho ou à não-atividade, já que, para esta parte da população, o corpo é feito para produzir. Quem adoece é visto como improdutivo, pois a concepção de doença, entre as camadas populares, é entrecortada pela noção físico-moral de que o fato de não trabalhar associa-se ao estar "fraco" (Campos, Soares, 2005; Oliveira, 1998; Minayo, 1997).

Uma outra particularidade pode ser considerada como relevante para a compreensão da doença, segundo os cuidadores: a religião. Dentre os entrevistados que freqüentavam igrejas evangélicas e centro espírita, o entendimento sobre o problema do usuário transitava entre a fé religiosa, a importância do trabalho (condições de vida da pessoa) e a constância em consultas médicas ou freqüência junto ao CAPS para o uso correto da medicação (seja para retirar uma receita, seja para receber gratuitamente o remédio), cuja supervisão será sempre realizada, no lar, pelo cuidador.

A importância da medicação apareceu em todas as entrevistas, entrecortando todas as formas de compreensão sobre maneiras de controlar ou curar a doença: o remédio é colocado como imprescindível para todos os tipos de tratamento realizados, seja médico ou religioso/espiritual. Se, em alguns momentos, o uso indevido da medicação foi visto como prejudicial ao bem-estar do usuário, em outros, a suspensão foi percebida de modo ameaçador, podendo fazer vir à tona os sintomas indesejados pela família.

Carvalho e Dimenstein (2004), ao discutirem o consumo de medicamentos ansiolíticos por mulheres em centros de saúde, ressaltam o impacto desta prática em nossa realidade, tendo em vista seu uso como recurso único de tratamento por um número significativo de pessoas que tem acesso apenas a esta forma de atendimento, pautada em consulta médica seguida de prescrição de receita, isto é, fundamentada numa compreensão de saúde limitada, que se arma da medicação como ferramenta principal.

Os cuidadores entrevistados descreveram a presença de sofrimento mental não apenas no usuário do CAPS, mas também na trajetória de outros familiares, incluindo, em alguns casos, os cuidadores. A presença de sofrimento mental associado à sobrecarga advinda da tarefa de cuidar, exercida por familiares de usuários do CAPS, coloca em foco a presença central do cuidador principal não apenas como suporte ao usuário, mas também ao seu grupo familiar. Geralmente exercido por mulheres, o cuidado ao usuário era uma das atividades pelas quais o entrevistado era responsável. A esta tarefa somavam-se inúmeras outras, como o cuidado com netos, liberando os pais dos mesmos para exercer trabalho, o cuidado com outros familiares adoecidos, a limpeza e organização do lar.

$\mathrm{Na}$ medida em que às dificuldades ou agruras do dia-a-dia somam-se episódios de sofrimento psíquico vividos pelas próprias cuidadoras, coloca-se em risco o principal suporte do usuário do CAPS. A presença da mulher como principal fonte de cuidados ao usuário de serviços de saúde mental já foi largamente apontada pela literatura (Pegoraro, Caldana, 2006; Campos, Soares, 2005; Lowyck et al., 2004; Lauber et al., 2003; Pereira, 2003; Rosa, 2003). No caso das famílias dos entrevistados, a situação de pobreza cotidiana implicava a somatória de dificuldades que iam muito além da convivência com o portador de doença mental, que, por si só, já pode ser vista como um fardo.

Além dos cuidados requeridos pelo usuário do CAPS e as demais tarefas cotidianas sob sua responsabilidade, alguns cuidadores depararam-se, ainda, com a ocorrência de sofrimento psíquico em familiares que Ihes serviam de apoio nos cuidados para com o usuário. Não raro o entrevistado tornou-se também referência para o cuidado deste outro familiar em sofrimento psíquico (marido, filhos, irmãs), assumindo uma maior carga de atividades. 
Quando o familiar em sofrimento mental era o próprio cuidador, o registro dessa ocorrência em período anterior à sobrecarga assinala, aos profissionais de saúde mental, a necessidade de um acompanhamento contínuo e próximo do dia-a-dia do cuidador. Com históricos de sofrimento mental descritos como "nervoso", depressão ou ideação suicida, os cuidadores, sobretudo aqueles com idade avançada, representam uma clientela, ao menos, indireta dos serviços de saúde mental.

A presença de sobrecarga, por si só, transformaria a família em cliente direto dos serviços públicos de saúde mental, merecedora de suporte para o enfrentamento de suas dificuldades (Campos, Soares, 2005; Rosa, 2005). O papel da equipe não pode centrar-se apenas na atenção ao usuário, e desligar-se da necessidade de apoio ao cuidador, cujas ações permitem a manutenção do usuário em atendimento em um serviço extra-hospitalar. O relato dos cuidadores a respeito de ocorrência de sofrimento mental em suas vidas, independente e anterior à sobrecarga, reafirma a posição da família como merecedora de atenção direta dos serviços, para que, identificada uma dificuldade maior, possa ocorrer o atendimento ou encaminhamento para o cuidado formal a este familiar.

Rosa (2005) aponta que as famílias mais pobres, como aquelas participantes deste estudo, e, em especial, os cuidadores apresentam-se aos serviços de saúde mental com uma bagagem que vai além da crise psiquiátrica: carregam as dificuldades da convivência com a doença mental vulnerabilizadas pelo seu contexto de vida, permeado pela pobreza e, quando não, pela exclusão social. Ao profissional de saúde, este momento de fragilidade deve ser visto como potencial para identificar a existência da rede de suporte social que ampare esta família ou não, bem como de sua dinâmica interna. Discurso recorrente por parte dos profissionais de saúde envolveria afirmações taxativas quanto à desorganização das famílias de camadas de baixa renda, sem a preocupação de conhecer seu cotidiano e seus recursos emocionais e financeiros para o exercício do cuidado. Não conseguindo a sua subsistência, esta população teria poucas condições para encarregar-se de um cuidado domiciliar de parentes que, além de não gerarem renda, demandam cuidados especiais.

A vulnerabilidade das famílias mais desfavorecidas que se responsabilizam por indivíduo adulto, improdutivo e que requer cuidados, em alguns casos constantes, não é discussão nova em nosso meio. Em 1993, Tsu já apontava para esta situação. Se à situação de vulnerabilidade não se somarem ações por parte dos profissionais de saúde, coloca-se em risco a intenção de desinstitucionalização da saúde mental no país, pois a família pode compreender que o usuário é mais um encargo com o qual deve lidar. O já clássico livro de Tsu (1993) relaciona os encargos emocionais e materiais com os cuidados aos usuários de famílias menos abastadas às solicitações dos familiares pela internação, como forma de divisão de encargos pelo paciente com o Estado.

É imprescindível que as equipes investiguem as concepções dos familiares sobre a saúde, a doença e seu tratamento, bem como seu contexto e condições de vida, para então informar a respeito do que se fizer necessário sobre o quadro, de modo a possibilitar que cada família elabore/encontre estratégias de convivência com o portador de sofrimento mental, especialmente em momentos em que encontra-se em crise.

\section{Considerações finais}

O atual panorama da atenção à saúde mental no Brasil traz à tona a posição da família na prestação de cuidados informais aos usuários de serviços extra-hospitalares. As famílias investigadas neste estudo, com base nos relatos dos familiares designados como principais cuidadores de usuários de um CAPS do interior paulista, apresentam dois importantes pontos de vulnerabilidade e que devem ser considerados pelas equipes de saúde mental. O primeiro ponto é a presença de sofrimento mental não apenas no usuário, mas também na trajetória de vida de outros familiares, incluindo-se, em alguns casos, o próprio cuidador. O segundo aspecto refere-se às dificuldades financeiras enfrentadas pelas famílias ao longo de sua trajetória, que podem interferir na prestação de cuidados.

Algumas situações de sofrimento psíquico presente nos familiares, e relatadas pelos cuidadores, teriam sido desencadeadas pela sobrecarga gerada pelo apoio no cuidado prestado ao usuário do CAPS. A presença de sofrimento mental em outros membros da família pode implicar mais sobrecarga para o 
cuidador, que tende a assumir, por estas pessoas, além das atividades cotidianas, a responsabilidade pelo usuário do CAPS.

A idade elevada da maior parte dos cuidadores, a presença de outros familiares com histórico de sofrimento psíquico e o uso de medicação psicotrópica por familiares e cuidadores podem ser tomados como indicativo da necessidade de intervenção das equipes de saúde junto às famílias, de forma a conhecer seu cotidiano e fornecer o suporte adequado. Os relatos dos cuidadores expõem a necessidade de atenção e intervenção, por parte das equipes de saúde, sobre a família do usuário a que atendem, de modo a também incluí-la no tratamento.

A investigação das histórias de vida dos cuidadores permite-nos lançar um olhar não apenas para a clientela direta (usuário) e indireta (familiares/rede social) dos serviços de saúde mental, mas, também, por meio da reflexão, contribuir para a ampliação da visão dos profissionais a respeito da maneira como a clientela entende e lida com o sofrimento psíquico.

Estratégias adequadas de atenção a estas famílias e aos usuários devem levar em conta a compreensão dessa clientela sobre a doença mental. As entrevistas aqui expostas apontaram para a centralidade do trabalho na vida dos cuidadores, permeando suas explicações a respeito do adoecimento mental, bem como sinalizando a possibilidade de cura do usuário. Apontamos, assim, para a importância do conhecimento do contexto de vida da clientela e seus cuidadores, por parte das equipes de saúde. São pessoas excluídas de um universo cultural, do qual fazem parte os profissionais que as atendem. No entanto, a partir do momento em que se passe a considerar a realidade na qual se inserem familiares e usuários, será possível, de modo mais efetivo, tanto transmitir as informações que as equipes julgam necessárias quanto traçar estratégias de atenção às famílias, importante recurso para o enfrentamento do sofrimento mental.

\section{Referências}

BANDEIRA, M.; BARROSO, S.M. Sobrecarga das famílias de pacientes psiquiátricos. J. Bras. Psiquiatr., v.54, n.1, p.34-46, 2005.

BERTAUX, D. L'approche biographique: sa valité méthodologique, ses potentialités. Cah. Int. Sociol., v.69, p.197-225, 1980.

BIASOLI-ALVES, Z.M.; DIAS DA SILVA, M.H.G.F. Análise qualitativa de dados de entrevista: uma proposta. Paidéia, n.2, p.61-9, 1992.

BRASIL. Ministério da Saúde. Portaria GM n. 336, de 19 de fevereiro de 2002. In: . Legislação em saúde mental: 1990-2004. Brasília, 2004. p.125-36.

Relatório final da III Conferência Nacional de Saúde Mental. Brasília, 11 a 15 de dezembro de 2002. Brasília: Conselho Nacional de Saúde/Ministério da Saúde, 2002.

CALDANA, R.H.L. Ser criança no início do século: alguns retratos e suas lições. 1998. Tese (Doutorado) - Centro de Educação e Ciências Humanas, Universidade Federal de São Carlos, São Carlos. 1998.

CAMPOS, P.H.F.; SOARES, C.B. Representação da sobrecarga familiar e adesão aos serviços alternativos em saúde mental. Psicol. Rev., v.11, n.18, p.219-37, 2005.

CARDOSO, M. Médicos e clientela: da assistência psiquiátrica à comunidade. São Carlos: Fapesp/EdUFSCar, 1999. 
CARVALHO, L.F.; DIMENSTEIN, M. O modelo de atenção à saúde e o uso de ansiolíticos entre mulheres. Estud. Psicol., v.9, n.1, p.121-9, 2004.

CESARINO, A.C. Hospital-dia "A Casa": conversando sobre dez anos de experiência. In: LANCETTI, A. (Org.). Saúdeloucura. São Paulo: Hucitec, 1989. v.1. p.33-45.

DEMARTINI, Z.B.F. Trabalhando com relatos orais: reflexões a partir de uma trajetória de pesquisa. In: LANG, A.B.S.G. (Org.). Reflexões sobre a pesquisa sociológica. São Paulo: CERU, 1992. p.42-60.

FERRARI, M.; KALOUSTIAN, S.M. Introdução. In: KALOUSTIAN, S.M. (Org.). Família brasileira: a base de tudo. São Paulo: Cortez, Brasília: Unicef, 1998. p.11-5.

FUREGATO, A.R.F. et al. O fardo e as estratégias da família na convivência com o portador de doença mental. Texto \& Contexto Enferm., v.11, n.3, p.51-6, 2002.

GONÇALVES, A.M.; SENA, R.R. A reforma psiquiátrica no Brasil: contextualização e reflexos com o cuidado do doente mental na família. Rev. Latinoam. Enferm., v.9, n.2, p.48-55, 2001.

KING, S. et al. Determinants of expressed emotion in mothers of schizophrenia patients. Psychiatry Res., n.117, p.211-22, 2003.

LAUBER, C. et al. Determinants of burden in caregivers of patients with exacerbating schizophrenia. Eur. Psychiatry, n.18, p.285-9, 2003.

LOWYCK, B. et al. A study of the family burden of 150 family members of schizophrenic patients. Eur. Psychiatry, n.19, p.395-401, 2004.

LUIS, M.V.; MARGIOTTE, M.S.; SANTOS, D.S.P. Percepções que a família e o paciente psiquiátrico têm sobre os determinantes de um distúrbio mental. Rev. Gaúcha Enferm. v.10, n.1, p.52-9, 1989.

MAGLIANO, L. et al. Family burden in long-term diseases: a comparative study in schizophrenia vs. physical disorders. Soc. Sci. Med., v.61, p.313-22, 2005.

MAURÁS, M.; KAYAYAN, A. Apresentação. In: KALOUSTIAN, S.M. (Org.). Família brasileira: a base de tudo. São Paulo: Cortez, Brasília: Unicef, 1998. p.9-10.

MELMAN, J. Família e doença mental: repensando a relação entre profissionais de saúde e familiares. São Paulo: Escrituras, 2002.

MINAYO, M.C.S. Representações da cura no catolicismo popular. In: MINAYO, M.C.S.; ALVES, P.C. (Orgs.). Saúde e doença: um olhar antropológico. Rio de Janeiro: Fiocruz, 1998. p.57-71.

Saúde e doença como expressão cultural. In: AMÂNCIO FILHO, A.; MOREIRA, M.C.G.B. (Orgs.). Saúde, trabalho e formação profissional. Rio de Janeiro: Fiocruz, 1997. p.31-9.

OLIVEIRA, F.J.A. Concepções de doença: o que os serviços de saúde têm a ver com isto? In: DUARTE, L.F.D.; LEAL, O.F. (Orgs.). Doença, sofrimento, perturbação: perspectivas etnográficas. Rio de Janeiro: Fiocruz, 1998. p.81-94.

OLIVEIRA, R.M.O.; LOYOLA, M.C. Família do paciente psiquiátrico: o retrato de uma ilustre desconhecida. Acta Sci. Health Sci., v.26, n.1, p.213-22, 2004.

OSINAGA, V.L.M. Saúde e doença mental: conceitos e assistência segundo portadores, familiares e profissionais. 1999. Dissertação (Mestrado) - Escola de Enfermagem de Ribeirão Preto, Universidade de São Paulo, Ribeirão Preto. 1999.

PEGORARO, R.F. Familiares que cuidam de portadores de sofrimento mental: histórias de dor, vidas de sofrimento. 2002. Dissertação (Mestrado) - Faculdade de Filosofia, Ciências e Letras de Ribeirão Preto, Universidade de São Paulo, Ribeirão Preto. 2002. 
PEGORARO, R.F.; CALDANA, R.H.L. Sobrecarga em familiares de usuários de um Centro de Atenção Psicossocial. Psicol. Estud., v.11, n.3, p.569-77, 2006.

PEREIRA, M.A.O. Representação da doença mental pela família do paciente. Interface Comunic., Saúde, Educ., v.7, n.12, p.71-82, 2003.

PINHO, L.B.; KANTORSKI, L.P. Refletindo sobre o contexto psicossocial de famílias de pacientes internados na unidade de emergência. Cienc. Enferm., v.10, n.1, p.67-77, 2004.

QUEIROZ, M.I.P. Relatos orais: do "indizível ao dizível". Cienc. Cult., v.39, n.3, p.272-86, 1987.

ROMANELLI, G. Políticas de saúde e famílias de classes populares. In: ENCONTRO ANUAL DA ANPOCS, 13., 1997, Caxambu. Palestra... Caxambu, 1997.

ROSA, L.C.S. A inclusão da família nos projetos terapêuticos dos serviços de saúde mental. Psicol. Rev, v.11, n.18, p.205-18, 2005.

Transtorno mental e o cuidado na família. São Paulo: Cortez, 2003.

E afinal, quem cuida dos cuidadores? In: BRASIL. III Conferência Nacional de Saúde Mental: cadernos de textos. Brasília: Ministério da Saúde, 2001.

ROSE, L.E.; MALLINSON, R.K.; GERSON, L.D. Mastery, burden, and areas of concern among family caregivers of mentally III persons. Arch. Psychiatr. Nurs., v.20, n.1, p.41-51, 2006.

TRAVERSO, M.Y.; MEDEIROS, L.F. Tremendo diante da vida: um estudo de caso sobre a doença dos nervos. Interações, v.9, n.18, p.87-108, 2004.

TSU, T. A internação e o drama das famílias. São Paulo: Edusp/Vetor, 1993.

PEGORARO, R.F.; CALDANA, R.H.L. Sufrimiento psíquico en familiares de usuarios de un Centro de Atención Psico-social. Interface - Comunic., Saúde, Educ., v.12, n.25, p.295-307, abr./jun. 2008.

Se investiga el sufrimiento en familiares de usuarios de un Centro de Atención Psicosocial del interior del estado de São Paulo, Brasil. Participaron del estudio nueve familiares identificados como cuidadores de dichos usuarios, en su mayoría del sexo femenino, con edades entre 60 y 76 años y pertenecientes a las camadas populares. Se utilizó un guión de entrevistas semi-estrutucturadas, abordando el relato libre de la historia de vida del cuidador, el sentido atribuido al cuidado y el impacto de la enfermedad mental en el cotidiano de los entrevistados y familiares. El análisis temático de las entrevistas ha permitido la identificación del sufrimiento psíquico (nervioso y depresión) en familiares, incluso cuidadores, y la realización de tratamiento psiquiátrico con uso de ansiolíticos. La presencia de sufrimiento mental en familiares, además del usuario, puede implicar más sobrecarga para el cuidador en virtud del acumulamiento de tareas e indica la necesidad de atención e intervención junto a las familias por parte de los equipos de salud.

Palabras clave: Cuidadores. Estrés psicológico. Salud mental. Relaciones familiares. 